\title{
Developing a Mathematical Model for the Controlled Release Over Time of Sulfentrazone Herbicide from Biodegradable Polymer
}

\author{
Gabriel Gouvêa Slade ${ }^{*}{ }^{\circledR}$, Sidney Macias Dourado Jr ${ }^{\circledR}$, Ronaldo Junio de Oliveira ${ }^{1}{ }^{\circledR}$, Jéferson Aparecido Moreto ${ }^{I *}$
}

\author{
${ }^{1}$ Departamento de Física, Instituto de Ciências Exatas, Naturais e Educação, Universidade Federal do \\ Triângulo Mineiro, Uberaba, MG, Brasil. \\ ${ }^{2}$ Instituto Federal de Educação, Ciência e Tecnologia Goiano, Rio Verde, GO, Brasil.
}

Received: April 25, 2019; Revised: August 28, 2019; Accepted: September 25, 2019.

In our research group, controlled release systems for the sulfentrazone herbicide has been accomplished by encapsulating this bioactive compound into calcium alginate (Ca-ALG) biodegradable polymer fashion and the release mechanisms were verified by using Korsmeyer-Peppas model (KP). However, the KP model does not allow to evaluate all the phenomena involved in the $\left(\mathrm{M}_{\mathrm{t}} / \mathrm{M}_{\infty}\right.$ versus $\left.\mathrm{t}\right)$ curves. Thus, the aim of this work is the development of a new mathematical model to interpret the distinct regions of the controlled release assays of the Sulfentrazone herbicide encapsulated in Ca-ALG microparticles and that can be used for other systems with a similar release profile. The proposed model is based on the herbicide diffusion, dissolution and polymer surface erosion. The results show that the proposed model is closest to the experimental curve when compared to the KP. The new mathematical model allows not just to describe the behavior of the system in terms of Fick's law, but to know what type of mechanism act in the herbicide release process.

Keywords: Controlled-release formulations; weed control; microparticulate system; leaching; Soil.

\section{Introduction}

The increase of world agriculture in productivity and cultivated areas occurs due to the adhesion of new technologies, such as the use of fertilizers, densified plantings, diffusion of transgenic plants and especially the use of agricultural pesticides ${ }^{1}$. Although the use of herbicides offers benefits in the economic and agronomic sectors, their increasing use cause damage to the environment, mainly due to the leaching process, which can lead to contamination of groundwater and soil ${ }^{2-6}$.

Herbicides are chemicals applied to eliminate losses of weed interference on crops and may be classified as carcinogenic, mutagenic, teratogenic and persisting in the environment ${ }^{7,8}$. The sulfentrazone, N-\{2,4-Dichloro-5-[4-(difluoromethyl)3-methyl-5-oxo-4,5-dihydro-1H-1,2,4-triazol-1-yl]phenyl\} methanesulfonamide, is a pre-emergent herbicide of the aryltriazolinones group, which acts by inhibiting the enzyme protoporphyrinogen oxidase, an important intermediate in the synthesis of chlorophyll in plants ${ }^{9}$ and may be applied in the conventional cultivation as in no-tillage system and used to weed control and some grasses in crops such as soybean ${ }^{10}$, chickpeas, sugarcane ${ }^{11}$ and rice ${ }^{12}$. Due to their intensive use, herbicides are often detected in surface and groundwater quality studies ${ }^{13}$. Figure 1 displays the molecular structure of the Sulfentrazone herbicide.

One way of minimizing the above-mentioned processes is through the encapsulation of these compounds in microparticulate system once the controlled release of herbicide is attractive to the agricultural sector ${ }^{14,15}$.

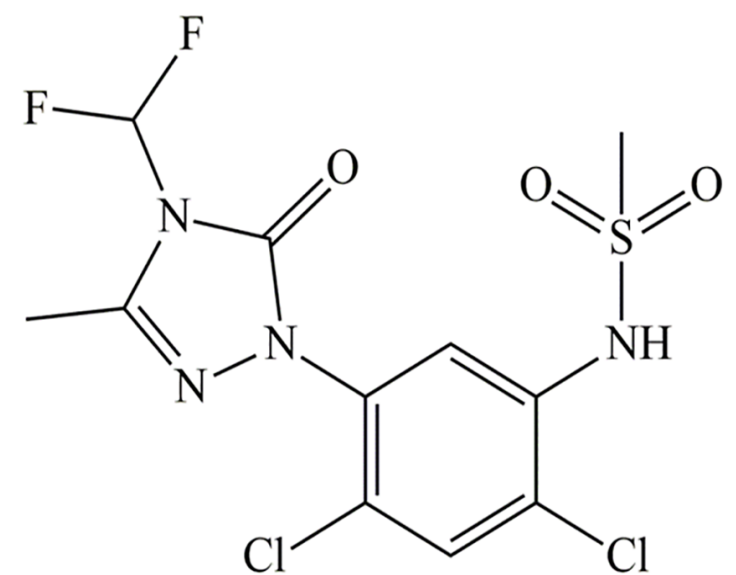

Figure 1. Molecular structure of the Sulfentrazone herbicide.

The encapsulation may be established as a process for confining active compounds within a particulate matrix ${ }^{16}$, to achieve one or more desirable effects. The particles can be used for immobilization, protection or stabilization, controlled release of the entrapped molecules, and for alteration of the characteristics of the active principle ${ }^{17}$.

Sodium alginate (Na-ALG) has been widely used in the encapsulation of active principle, by protecting the encapsulated compounds from adverse factors such as temperature, humidity and $\mathrm{pH}$, improving stability and bioavailability. $\mathrm{Na}-\mathrm{ALG}$ is an abundant polysaccharide of natural origin, is odorless and non-toxic, and can be taken from brown seaweed (Phaeophyceae), and certain species of bacteria ${ }^{18}$. 
Na-ALG has interesting properties that allow industrial applications, such as: gelling and thickening performance, biodegradability, biocompatibility, ability to accumulate water, and non-toxicity. Its application can be found in the cosmetics industry, in the agricultural sector as a pesticide and nutrient release agent, and in the food industry as protective edible films and a thickening agent with indistinguishable flavor. ALG-Na is a biopolymer of linear chains soluble in an aqueous medium, and is composed of several units of $\beta$-D-mannuronic (M) and $\alpha$-L-guluronic acid $(\mathrm{G})$, linked by glycosidic bonds $(1 \rightarrow 4)$, composition and sequence ${ }^{19}$. Figure 2 shows the chemical structure of Na-ALG polymer.

In a previous work ${ }^{14}$, we studied a novel green process to obtain a controlled release of Sulfentrazone herbicide encapsulated into the Ca-ALG microparticles and evaluated the phytotoxicity in different concentrations of herbicide and the relation with the depth of leaching, using bioindicator plants. Our research group fitted the results by using KorsmeyerPeppas model (KP) for the $60 \%$ release of herbicide and did not verify at the time the main phenomena involved with a set of experimental data in a specific interval of time in the release curves $\left(\mathrm{M}_{\mathrm{t}} / \mathrm{M}_{\infty}\right.$ versus $\left.\mathrm{t}\right)$. This fact motivated the search for a new model that could be capable to describe the release mechanism in such conditions.

The use of mathematical models applied to describe the controlled release, besides helping the knowledge of the mechanisms of mass transfer, allows the reduction of the number of experimental tests, once the profile of the release of an active compound by polymeric matrices can be predicted using an approximate calculation ${ }^{20,21}$.
Here, we developed a mathematical model that has a much better adjustment to the experimental data points over time and, at the same time, uncovers the different mechanisms involved in the product release. This model is based on the herbicide diffusion, dissolution and polymer surface erosion, and when it was compared to the experimental curve allowed us to infer in the release mechanism.

\section{Material \& Methods}

All reagents used in the work cited were of analytical grade. The Na-ALG was kindly provided by Sigma-Aldrich (Brazil) with molecular weight (M/W) of 100,000 $\mathrm{g} \mathrm{mol}^{-1}$, viscosity of 15-20 cP, 61\% mannuronic acid and 39\% guluronic acid. Calcium chloride, $\mathrm{CaCl}_{2}$ (Sigma - Aldrich), sodium chloride, $\mathrm{NaCl}$ (Sigma Aldrich) and deionized water (Milli-Q system (Millipore)) were also used to obtain Ca-ALG microparticles.

The apparatus used in this work was built on the basis of studies developed by Dias et al ${ }^{22}$, Shi et al ${ }^{23}$ and Faria ${ }^{24}$. For this purpose, solution of Na-ALG $(3 \% \mathrm{~m} / \mathrm{v})$ and concentration of $0.1 \mathrm{~mol} \mathrm{~L}^{-1}$ of $\mathrm{CaCl}_{2}$ were prepared. In sequence, Na-ALG containing sulfentrazone herbicide (6 $\mathrm{g} \mathrm{L}^{-1}$ of concentration) was dropped in $\mathrm{CaCl}_{2}$ solution, resulting in a total of 100 microparticles of Ca-ALG. Figure 3 displays the schematic representation of Ca-ALG microparticles preparation by ionotropic gelation method.

According to Dourado $\mathrm{Jr}$ et $\mathrm{al}^{13}$, in order to improve microparticle texture and roundness, the $\mathrm{Na}-\mathrm{ALG}$ solution was adjusted with $0.1 \mathrm{~mol} \mathrm{~L}^{-1}$ of sodium chloride $(\mathrm{NaCl})$ and new batches of microparticles were prepared using same conditions as described before.

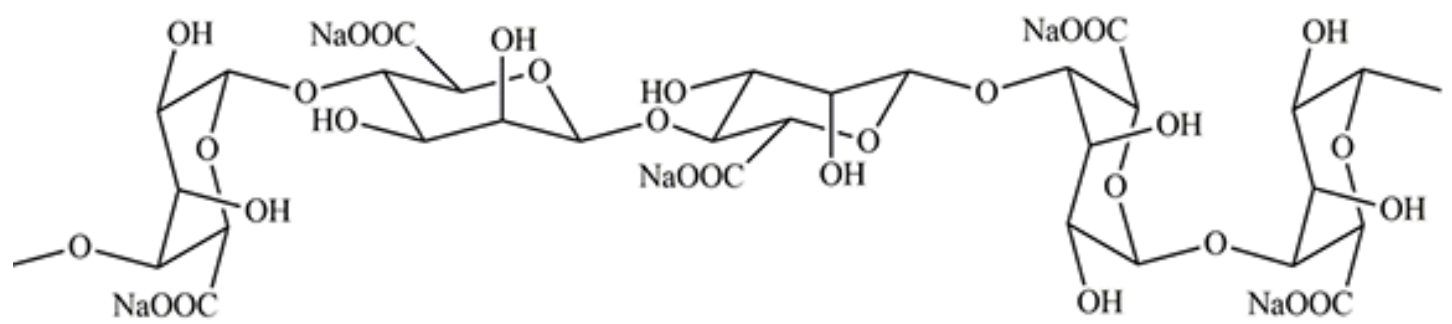

Figure 2. Molecular structure of Na-ALG polymer.
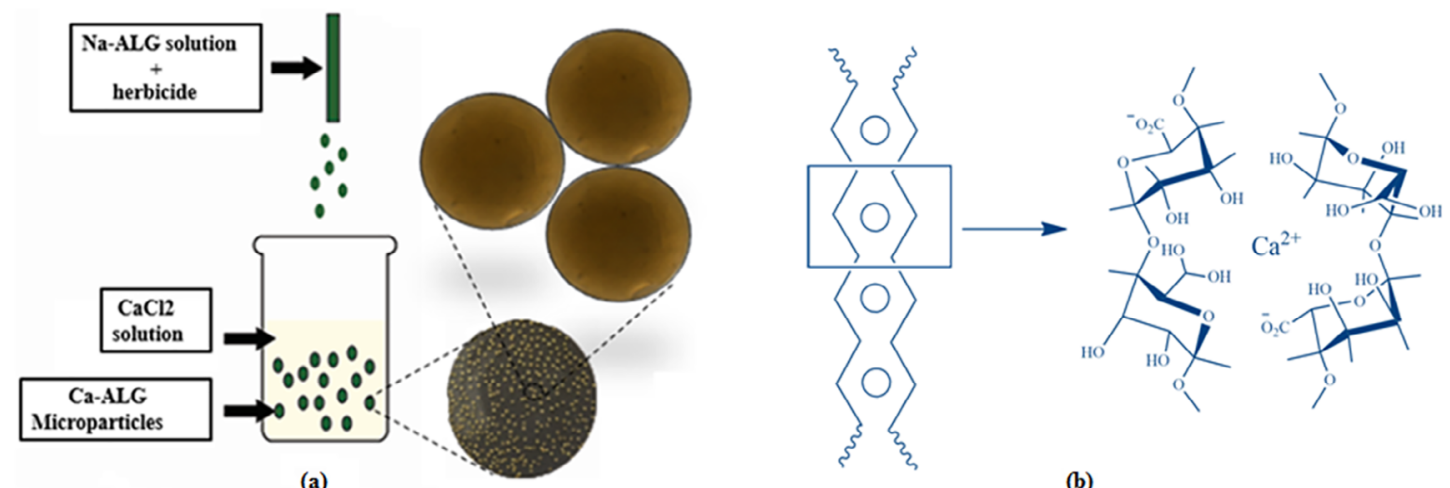

(b)

Figure 3. (a) Schematic drawing of the production of Ca-ALG microparticles containing the herbicide Sulfentrazone by ionotropic gelation method and (b) alginate hydrogels prepared by ionic cross-linking (egg-box model). 
The Ca-ALG microparticles was stored in deionized water and passed through a process of water exchange during 3 days. This procedure was used to eliminate the $\mathrm{NaCl}$ content on the Ca-ALG microparticles.

The encapsulation efficiency (\% EE) was evaluated by the difference of the amount of herbicide added in the $\mathrm{Na}-\mathrm{ALG}+$ Sulfentrazone solution and the unentrapped amount of sulfentrazone remaining in the supernatant after the removal of the formed microparticles, following the equation:

$\% \mathrm{EE}=\left[\frac{\text { Sulfentrazone added }- \text { free unentrapped Sulfentrazone }}{\text { Sulfentrazone added }}\right] \times 100 \%$

The surface morphology of Sulfentrazone-loaded were studied by using a scanning electron microscope (SEM - JEOL JSM6601LV) and an optical microscopy (OM) using a microscopy Olympus with 10x magnification. The Ca-ALG microparticles containing the Sulfentrazone herbicide were mounted on an appropriate stub and coated with $\mathrm{Au}$ and then observed via SEM. In addition, the particle size of sulfentrazone-loaded Ca-ALG beads was carried out by using SEM, OM and imageJ software.

To understand the mechanisms of controlled release of the sulfentrazone herbicide encapsulated in Ca-ALG microparticles, our research group fitted the results by using Korsmeyer-Peppas model (KP) for the $60 \%$ release of herbicide and did not verify at the time the main phenomena involved in the distinct regions of the release curves $\left(\mathrm{M}_{t} \mathrm{M}_{\infty}\right.$ versus $\left.\mathrm{t}\right)$. This fact motivated the search for a new model that could be capable to describe the release mechanism in such conditions.

Here, we present a model of herbicide release from biodegradable polymeric microspheres with surface erosion. In this process, the hydrolysis of the polymeric matrix mainly occurs in the region near the surface. The microsphere gradually decreases in size but maintains its shape and structural integrity throughout the erosion process. As the surface is eroded, the herbicide dissolves into the release medium and diffuse toward the external solution. A description of the mathematical model used to explain the mechanisms of controlled release of sulfentrazone herbicide encapsulated in microparticles of Ca-ALG polymer follows below.

\subsection{Model Description}

The model is based on the previous work of Zhang et al ${ }^{25,26}$ where it is used to characterize the drug release from porous and biodegradable microspheres. Here, the model is used to understand the mechanisms of controlled release of sulfentrazone herbicide encapsulated into Ca-ALG polymer. Basically, the overall release mechanisms can be described by herbicide diffusion, herbicide dissolution and polymer surface erosion.
In the polymer microsphere, the herbicide concentration presents both liquid and solid phase. The concentration in liquid phase is related to the herbicide in solution and is determined by diffusion and dissolution processes during the time, while the solid one is related to the herbicide in the polymer matrix and is controlled only by dissolution.

The initial form of governing equation for liquid phase concentration is

$$
\frac{\partial C_{L}}{\partial t}=D \frac{1}{r^{2}} \frac{\partial}{\partial r}\left(r^{2} \frac{\partial C_{L}}{\partial r}\right)+k_{d i s}\left(\varepsilon C_{s a t}-C_{L}\right)
$$

where $C_{L}$ is the herbicide concentration in the liquid phase, $C_{\text {sat }}$ is the herbicide saturation concentration, $r$ is the radial position of microsphere, $\varepsilon$ is the porosity of polymer, $k_{d i s}$ is the herbicide dissolution rate and $D$ is the effective diffusivity in the polymer matrix. For the model, this equation obeys the following initial conditions (IC) and boundary conditions $(\mathrm{BC})$

$$
\begin{gathered}
\text { IC: } C_{L}=0,\left(t=0,0 \leq r \leq R_{t}\right), \\
\text { BC: } \frac{\partial C_{L}}{\partial r}=0,(t>0, r=0), \\
\text { BC: } C_{L}=C_{\infty},\left(t>0, r=R_{t}\right),
\end{gathered}
$$

where $R_{t}$ is the instantaneous radius of microsphere and $C_{\infty}$ is the drug concentration in external medium.

For the solid phase concentration, the corresponding equation is given by

$$
\frac{\partial C_{S}}{\partial t}=-k_{d i s}\left(\varepsilon C_{s a t}-C_{L}\right)
$$

where $C_{S}$ is the herbicide concentration in the solid phase. For the model, this equation obeys the following initial conditions (IC)

$$
\text { IC: } C_{S}=C_{0}-C_{s a t},\left(t=0,0 \leq r \leq R_{t}\right),
$$

where $C_{0}$ is the initial concentration in the polymer microsphere.

Based on experimental data ${ }^{27-31}$, the polymer erosion can be described by three different ways. The first one is a linear reduction in radius, $R=R_{0}\left(1-k_{\text {ero }} t\right)$ where $k_{\text {ero }}$ is an erosion rate constant (case I). The second is a power-type relation between volume and time that implies a reduction in radius like $R=R_{0}\left(1-k_{\text {ero }} t\right)^{\frac{a}{3}}$, where $a$ is a parameter to be found from regression of weight loss data and commonly ranges from 2 to 8 (case II). Higher values of denote a quicker weight loss rate of polymer microspheres. The last is a root-type relation between volume and time where the reduction in radius is $R=R_{0}\left(1-\left(k_{\text {ero }} t\right)^{a}\right)^{\frac{1}{3}}$ with smaller than 1 , often in the range 0.1-0.5 (case III). In this case, higher values of $a$ denote a slower weight loss rate. The parameters $a$ and $k_{\text {ero }}$ depend on the polymer matrix composition and crystallinity ${ }^{26}$. 
Since the reduction in radius is time dependent, it is necessary to convert the moving boundary problem to a fixed boundary problem. So, the radial position is normalized with respect the instantaneous radius of the microsphere. In case I, let $s=\frac{r}{R}=\frac{r}{R_{0}\left(1-k_{\text {ero }} t\right)}, u_{L}=\frac{C_{L}-C_{\infty}}{C_{0}-C_{\infty}}, u_{S}=\frac{C_{S}-C_{\infty}}{C_{0}-C_{\infty}}$, $w=k_{\text {ero }} t, E_{r}=\frac{k_{\text {ero }} R_{0}^{2}}{D}, p=\frac{k_{\text {dis }}}{k_{\text {ero }}}$ and $q=\frac{\varepsilon C_{\text {sat }}-C_{\infty}}{C_{0}-C_{\infty}}$, where $u_{L}$ and $u_{S}$ are the dimensionless concentration in the liquid and solid phase. With these transformations, equation 2 becomes

$$
\begin{aligned}
\frac{\partial u_{L}}{\partial w} & =\frac{1}{E_{r}(1-w)^{2} s^{2}} \frac{\partial}{\partial s}\left(S^{2} \frac{\partial u_{L}}{\partial s}\right) \\
& +p\left(q-u_{L}\right)-\frac{\partial u_{L}}{\partial s} \frac{s}{1-w} .
\end{aligned}
$$

Consequently, the initial and boundary conditions are given by

$$
\begin{gathered}
\text { IC: } \left.u_{L}=0, w=0,0 \leq s \leq 1\right), \\
\text { BC: } \frac{\partial u_{L}}{\partial s}=0,(t>0, s=0), \\
\text { BC: } \left.u_{L}=0, t>0, s=1\right),
\end{gathered}
$$

For the solid phase, the equation 6 becomes

$$
\frac{\partial u_{S}}{\partial w}=-p\left(q-u_{L}\right)
$$

with initial condition

$$
\mathrm{IC}: u_{S}=1,(w=0,0 \leq s \leq 1) .
$$

In case II and III, the parameter is written as $s=\frac{r}{R_{0}\left(1-k_{\text {ero }} t\right)^{\frac{a}{3}}}$ and $s=\frac{r}{R_{0}\left(1-\left(k_{\text {ero }} t\right)^{a}\right)^{\frac{1}{3}}}$, respectively. With the same transformations did in case I, $u_{L}=\frac{C_{L}-C_{\infty}}{C_{0}-C_{\infty}}, u_{S}=\frac{C_{S}-C_{\infty}}{C_{0}-C_{\infty}}, w=k_{\text {ero }} t, E_{r}=\frac{k_{\text {ero }} R_{0}^{2}}{D}, p=\frac{k_{\text {dis }}}{k_{\text {ero }}}$ and $q=\frac{\varepsilon C_{s a t}-C_{\infty}}{C_{0}-C_{\infty}}$, the corresponding governing equations for the liquid phase can be written as

$$
\begin{gathered}
\text { Case II: } \frac{\partial u_{L}}{\partial w}=\frac{1}{E_{r}(1-w)^{2} s^{2}} \frac{\partial}{\partial s}\left(s^{2} \frac{\partial u_{L}}{\partial s}\right) \\
+p\left(q-u_{L}\right)-\frac{a s}{3(1-w)} \frac{\partial u_{L}}{\partial s} \\
\text { Case III } \frac{\partial u_{L}}{\partial w}=\frac{1}{E_{r}\left(1-w^{a}\right)^{2 / 3} s^{2}} \frac{\partial}{\partial s}\left(s^{2} \frac{\partial u_{L}}{\partial s}\right) \\
+p\left(q-u_{L}\right)-\frac{a w^{a-1} s}{3\left(1-w^{a}\right)} \frac{\partial u_{L}}{\partial s},
\end{gathered}
$$

with the same governing equations for the solid phase (once they do not have dependence in radius), IC and BC.
One important variable for this kind of problem is the herbicide release percentage $\left(M / M_{\infty}\right)$, where $M_{t}=\int\left(C_{0}-C_{\infty}\right)$ $d V-\int\left(C_{L}+C_{S}-2 \mathrm{C}_{\infty}\right) d V$ and $M_{\infty}=\int\left(C_{0}-C_{\infty}\right) d V$ are the remaining and total amount of herbicide in the polymer microspheres, respectively. This quantity includes the amount of herbicide from both the liquid and solid phases that has exited the instantaneous external boundary of the microsphere and is computed as:

$$
\frac{M_{t}}{M_{\infty}}=1-\frac{\int_{0}^{R}\left(C_{L}+C_{S}-2 C_{\infty}\right) 4 \pi r^{2} d r}{\frac{4}{3} \pi R_{0}^{3}\left(C_{0}-C_{\infty}\right)}
$$

For each case, this quantity can be written as

$$
\begin{aligned}
& \text { Case I: } \frac{M_{t}}{M_{\infty}}=1-3(1-w)^{3} \int_{0}^{1}\left(u_{L}+u_{S}\right) s^{2} d s \\
& \text { Case II: } \frac{M_{t}}{M_{\infty}}=1-3(1-w)^{a} \int_{0}^{1}\left(u_{L}+u_{S}\right) s^{2} d s \\
& \text { Case III: } \frac{M_{t}}{M_{\infty}}=1-3\left(1-w^{a}\right) \int_{0}^{1}\left(u_{L}+u_{S}\right) s^{2} d s
\end{aligned}
$$

Derivation of dimensionless governing equations used in the present work may be checked in supporting information (SI).

\section{Results \& Discussion}

Our group developed an effective controlled release system using the Sulfentrazone herbicide encapsulated into $\mathrm{Ca}-\mathrm{ALG}$ polymer fashion with high prospects in agriculture area. As already mentioned, Sulfentrazone herbicide was encapsulated in Ca-ALG beads prepared with Na-ALG by the ionotropic gelation method, using $\mathrm{CaCl}_{2}$ as a crosslinking agent. Controlled release assays were also performed and the release mechanisms were verified by using the KP model. Further information can be obtained from the work developed by Dourado Jr et al ${ }^{14}$.

Regarding the mathematical model for the controlled release over time of Sulfentrazone herbicide from biodegradable polymer developed in the present work, the governing equations were solved numerically using the PDE solver of MATLAB and the results are shown in terms of the normalized herbicide release percentage in function of the normalized time for each case in comparison with the experimental data. Figure 4 shows the desired curves for the three different surface erosion cases: linear (Case I), power type (Case II) and root type (Case III) relations. Based on previous works $^{23,24}$, the behavior of the experimental data and a set of preliminary computational convergence tests, the parameters used were $E_{r}=0.8, p=50$ and $q=0.06$. 

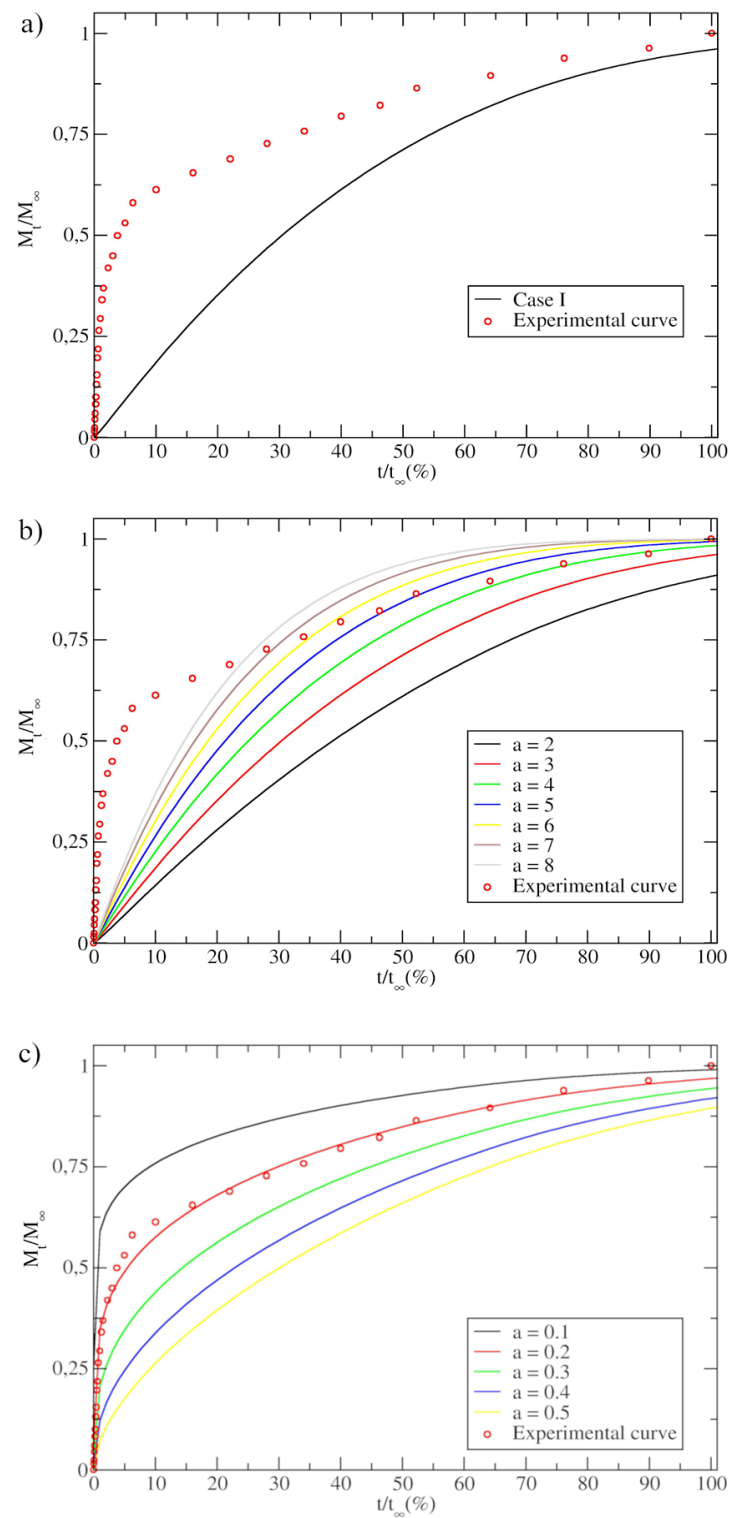

Figure 4. Herbicide release percentage as function of the normalized time. (a) Linear, (b) power type and (c) root type relations. The parameters used were $E_{r}=0.8, p=50$ and $q=0.06$. For the power and root type relations, the parameter $a$ was varied between $2-8$ and $0.1-0.5$, respectively. The red circles represent the experimental data.

Here is important to highlight some points about the meaning of these parameters: $E_{r}$ denotes the relative importance between polymer erosion and herbicide diffusion, $p$ represents the relation between the herbicide dissolution and polymer erosion, and $q$ indicates the ratio of herbicide saturation concentration to initial herbicide loading. For the power and root type relations, the parameter $a$ was varied between 2-8 and 0.1-0.5, respectively. The comparison among the type of surface erosion shows that the studied system obeys a root type relation. Based on previous work ${ }^{26}$, this result indicates that in the beginning of the release process the erosion occurs in a fast way and after it slow down.
The KP model ${ }^{32}$ is a well-known model used to describe the release mechanism of an active ingredient and it follows the equation

$$
\frac{M_{t}}{M_{\infty}}=K t^{n}
$$

where $K$ is the kinetic constant and $n$ is the exponent which reflects the type of release mechanism. Values of $n \leq 0.43$ are an indicative of a release mechanism that follows the Fick's Law, $n>0.85$ indicates that the mechanism are governed by relaxation processes of the polymeric matrix and an intermediate value suggests anomalous behavior with non-Fickian release.

As cited before, in a previous work ${ }^{14}$ the experimental data was fitted by KP model for the $60 \%$ release of herbicide. The model showed that the diffusion parameter is about $n=0.2866$ indicating that the release mechanism of the herbicide follows the Fick's law. A comparison of KP model and the proposed one can be seen in Figure 5. It is possible note that the proposed model provides a best fit in comparison with the experimental curve. With this new approach, that takes in account three steps in the release mechanism, it is possible to infer that the release of herbicide in this studied case not just depends on diffusion, but the surface erosion and herbicide dissolution play an important role too. It is known ${ }^{26}$ that higher values of the parameters $E_{r}$ and $p$ means that: 1) the polymer erosion process is faster than the herbicide diffusion process and 2) the herbicide is more quickly dissolved and its effects are stronger during the early stages of the release process. So, in the begging of the process, the surface erosion happens in a fast way and consequently, the dissolution of the herbicide into liquid phase is observed. After that, the erosion process slow down and the herbicide diffusion dominates the process. Thus, besides the mathematical model presented here shows a better adjustment to the experimental data points over time when compared to the KP model, it is still capable to give a better insight on the controlled release mechanisms of the Sulfentrazone herbicide into Ca-ALG microparticles.

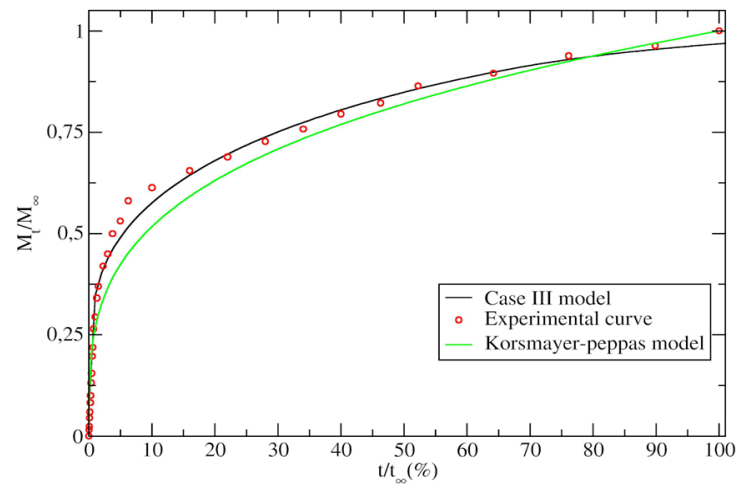

Figure 5. Herbicide release percentage as function of the normalized time. The parameters used for the root type relation were $E_{r}=0.8$, $p=50, q=0.06$ and $a=0.2$. Black curve represents the case III model, the green one the Korsmeyer-Peppas model and the red circles represent the experimental data. 


\section{Conclusions}

In a previous work, we studied experimentally the release assays of sulfentrazone herbicide encapsulated into Ca-ALG microparticles for weed control. In that work, the experimental data points obtained for the release in time were adjusted by the KP model, which is an equation commonly employed for linearization of release data of unknown mechanism. Here, we proposed a model that is solved numerically based on the combination of three steps: herbicide diffusion, herbicide dissolution and polymer surface erosion. The results showed that in the begging of the release process, the dominant aspects are the polymer erosion and herbicide dissolution. After that, the erosion process slow down and the herbicide diffusion dominates the process. When compared to KP model, the proposed model most closely matches the experimental data. In this sense, the proposed model can be used to better understand the release of the sulfentrazone herbicide encapsulated in the biodegradable polymer fashion. Besides that, further studies can be done in order to describe the characteristics of the polymer matrix.

\section{Acknowledgements}

The authors gratefully acknowledge MSc. Sidney Macias Dourado Júnior by the experimental release curves and professor Chi-Hwa Wang of Department of Chemical and Environmental Engineering at National University of Singapore for help in mathematical modeling and providing the numerical source. This research was supported by the funding agencies, Fundação de Amparo à Pesquisa do Estado de Minas Gerais (FAPEMIG, No. APQ-00941-14) and the Conselho Nacional de Desenvolvimento Científico e Tecnológico (CNPq, No. 438316/2018-5), and the authors thank the facilities Núcleo de Computação Científica da Universidade do Estado de São Paulo (NCC/GridUNESP) and Centro Nacional de Processamento de Alto Desempenho em São Paulo (CENAPAD-SP) for computational resources.

\section{References}

1. Fernandes DOM, Brighenti AM. Comportamento dos Herbicidas no Ambiente. Campinas: EMPRAPA; 2011.

2. Konstantinou IK, Hela DG, Albanis TA. The status of pesticide pollution in surface waters (rivers and lakes) of Greece. Part I. Review on occurrence and levels. Environmental Pollution. 2006;141(3):555-70.

3. Carter AD. Herbicide movement in soils: Principles, pathways and processes. Weed Research. 2002;40(1):113-122.

4. Cerejeira MJ, Viana P, Batista S, Pereira T, Silva E, Valerio MJ, et al. Pesticides in Portuguese surface and ground waters. Water Research. 2003;37(5):1055-63.
5. Planas C, Caixach J, Santos FJ, Rivera J. Occurrence of pesticides in Spanish surface waters. Analysis by high-resolution gas chromatography coupled to mass spectrometry. Chemosphere. 1997;34(11):2393-2406.

6. Richardson ML. Chemistry, Agriculture and the Environment. Cambridge: Royal Society of Chemistry; 1991.

7. Katz H, Mishael YG. Reduced herbicide leaching by in situ adsorption of herbicide-micelle formulations to soil. Journal of Agricultural and Food Chemistry. 2014;62(1):50-7.

8. Gonçalves FF. Estudo de métodos empregando HPLC-DAD e LC-MS/MS para determinação de resíduos de herbicidas em água e solo do cultivo de arroz irrigado [tese]. Santa Maria (RS): Universidade Federal de Santa Maria - UFSM; 2007.

9. Jacobs JM, Jacobs NJ. Oxidation of protoporphyrinogen to protoporphyrin, a step in chlorophyll and haem biosynthesis. Biochemical Journal. 1987;244(1):219-224.

10. Belfry KD, McNaughton KE, Sikkema PH. Weed control in soybean using pyroxasulfone and sulfentrazone. Canadian Journal of Plant Science. 2015;95(6):1199-1204.

11. Carbonari CA, Gomes CLGC, Trindade MLB, Silva JRB, Velini ED. Dynamics of sulfentrazone applied to sugarcane crop residues. Weed Science. 2016;64(1):201-206.

12. Duart VM, Duart AM, Tramontin MT, Spannemberg R, Garbuio FJ. Controle de plantas daninhas em pré emergência em sistema de semeadura de arroz em solo seco. Revista Técnico Cientifica do IFSC. 2013;1(5):49.

13. Tanabe A, Mitobe H, Kawata K, Yasuhara A, Shibamoto T. Seasonal and spatial studies on pesticide residues in surface waters of the Shinano River in Japan. Journal of Agricultural and Food Chemistry. 2001;49(8):3847-52.

14. Dourado Junior SM, Nunes ES, Marques RP, Rossino LS, Quites FJ, Siqueira Junior JR, et al. Controlled release behavior of sulfentrazone herbicide encapsulated in Ca-ALG microparticles: preparation, characterization, mathematical modeling and release tests in field trial weed control. Journal of Materials Science. 2017;52(16):9491.

15. Daitx TS, Giovanela M, Carli LN, Mauler RS. Biodegradable polymer/clay for systems highly controlled release of NPK fertilizer. Polymers for Advanced Technologies. 2018;30(3):1-9.

16. Neri-Badang MC, Chakraborty S. Carbohydrate polymers as controlled release devices for pesticides. Journal of Carbohydrate Chemistry. 2019;38(1):67-85.

17. Santos RSB. Estudo dos fatores que influenciam os atributos de esferas de alginato [dissertação]. Portugal: Universidade de Aveiro - Departamento de Química; 2012.

18. Zeeb B, Saberi AH, Weiss J, McClements DJ. Formation and characterization of filled hydrogel beads based on calcium alginate: Factors influencing nanoemulsion retention and release. Food Hydrocolloids. 2015;50:27-36.

19. Souza ELC, Foloni LL, Mantovani EC, Teixeira Filho J. Comportamento do tebuthiuron em solo de cultivo de canade-açúcar utilizando lisímetro de drenagem modificado. Planta Daninha. 2008;26(1):157-163. 
20. Oliveira SC, Pereira FM, Ferraz A, Silva FT, Gonçalves AR. Mathematical Modeling of Controlled-Release Systems of Herbicides Using Lignins as Matrices. Applied Biochemistry Biotechnology. 2000;84-86:595-615.

21. Arifin DY, Lee LY, Wang CH. Mathematical modeling and simulation of drug release from microspheres: Implications to drug delivery systems. Advanced Drug Delivery Reviews. 2006;58(12-13):1274-325.

22. Dias FS, Queiroz DC, Nascimento RF, Lima MB. Um sistema simples para preparação de microesferas de quitosana. Química Nova. 2008;31(1):160-163.

23. Shi LE, Fang XJ, Xing LY, Chen M, Zhu DS, Guo XF, et al. Chitosan nanoparticles as drug delivery carriers for biomedical engineering. Journal of Chemical Society of Pakistan. 2011;33(6):929-934.

24. Faria DM. Obtenção e caracterização de micropartículas de alginato para a liberação controlada do herbicida tebuthiuron [dissertação]. Rio Verde: Instituto Federal Goiano, Campus Rio Verde; 2016.

25. Zhang M, Yang Z, Chow LL, Wang CH. Simulation of drug release from biodegradable polymeric microspheres with bulk and surface erosions. Journal of Pharmaceutical Sciences. 2003;92(10):2040-56.

26. You S, Yang Z, Wang CH. Towards understanding drug release from biodegradable polymer microspheres of different erosion kinetics modes. Journal of Pharmaceutical Sciences. 2016;105(6):1934-46.
27. Chia HH, Yang YY, Chung TS, Ng S, Heller J. Auto-catalyzed poly(ortho ester) microspheres: a study of their erosion and drug release mechanism. Journal of Controlled Release. 2001;75(1-2):11-25.

28. Chiba M, Hanes J, Langer R. Controlled protein delivery from biodegradable tyrosine-containing poly(anhydride-co-imide) microspheres. Biomaterials. 1997;18(13):893-901.

29. Hanes J, Chiba M, Langer R. Degradation of porous poly(anhydrideco-imide) microspheres and implications for controlled macromolecule delivery. Biomaterials. 1998;19(1-3):163-72.

30. Shieh L, Tamada J, Tabata Y, Domb A, Langer R. Drug release from a new family of biodegradable polyanhydrides. Journal of Controlled Release. 1994;29(1-2):73-82.

31. Wan JP, Yang YY, Chung TS, Tan D, Ng S, Heller J. POE-PEGPOE triblock copolymeric microspheres containing protein II. Polymer erosion and protein release mechanism. Journal of Controlled Release. 2001;75(1-2):129-141.

32. Korsmeyer RW, Gurny R, Doelker EM, Buri P, Peppas NA. Mechanism of solute release from porous hydrophilic polymers. International Journal of Pharmaceutics. 1983;15(1):25-35.

\section{Supplementary material}

The following online material is avaliable for this article: Appendix - Derivation of Dimensionless Governing Equations 